Journal of Engineering and Applied Sciences 14 (17): 6312-6316, 2019

ISSN: 1816-949X

(C) Medwell Journals, 2019

\title{
Investigation of Blocks Performance at Stilling Basin using Computation Fluid Dynamics
}

\author{
Haitham A. Huseein and Sarab A. Mohsen \\ Department of Civil Engineering, Al-Nahrain University, Al-Jadriya, Baghdad, Iraq
}

\begin{abstract}
Blocks are used at stilling basins to decrease the high flow velocity and dissipate energy at hydraulic structures. In this study, a comparison between physical and Computational Fluid Dynamic (CFD) Model at stilling basin blocks are conducted. The aim of percent CFD Model is to show the application of the finite element method for the solution of fluid flow problems. In addition, investigate and validate theoretical work by ANSYS program solutions with previous experiment results. A free surface (CFD) Model based on the Volume of Fluid (VOF) method and characteristic of the turbulence k- $\varepsilon$ Model has been applied. Finally, the results of physical model and (CFD) have been compared to study whether the results come to a good agreement.
\end{abstract}

Key words: Stilling basin, dissipation of energy, baffle blocks, CFD, fluid flow, blocks

\section{INTRODUCTION}

To reduce the flow velocity on hydraulic structure like sluice gate, a stilling basin with blocks are used. There are many types of blocks such as chute blocks and baffle blocks. The effect of the configurations and the dimensions of the buffer blocks on the flow velocity are concluded and the stilling basin performance decrease when the space between the blocks are increase. In addition when the block dimensions increased the stilling basin performance be low flow velocity (Rozainy et al., 2017). The curved blocks have a significant effect on the energy dissipation than the normal blocks where they contribute to increase the efficiency of the stilling basin because it reduces the cost of maintenance (Eloubaidy et al., 1999). The sloping face blocks are found to be more effective than those of the vertical or a roughened bed in increasing the reduction of the length of the hydraulic jump (Bessaih and Rezak, 2002). The effect of semi circular blocks that placed in an orderly manner reduced the length and the depth of the hydraulic jump, this reflects the economic because it leads to reducing the cost of maintenance (Abdelhaleem, 2013). The energy dissipater, the crest and the chute are sections of an overflow spillway at the end of the downstream. The design of the crest is to amplify the capacity of the discharge of spillway. The design of the chute is to carry the water of a flood above the dam and the design of the energy dissipater is to minimize the flow kinetic energy at the downstream end of the chute
(Chanson, 2004). The water was released from the hydraulic structures where the stilling basins are used for this purpose to form a hydraulic jump in order to transfer the water movement from critical to sub-critical. The forms of the block and its effect on the flow are identified under the gate by conducting some laboratory experiments using three discharges and three depths for different types of tail water and found that the baffle blocks have a significant effect in reducing the flow at the gate and proved that energy dissipation is inversely proportional to discharges of $<75 \mathrm{~L} / \mathrm{sec}$ (Ibrahim, 2017).

The aim of this study is to simulate the numerical solution of computation fluid dynamics with the previous experiment research and comparison the results of mathematical and physical model to adopt ANSYS program for another cases solutions.

\section{MATERIALS AND METHODS}

Work description: In this study, the sluice gate have been set to enter the water with a height of $3 \mathrm{~cm}$ from the bottom of the channel and the water exit gate was $25 \mathrm{~cm}$ high. Three baffle blocks were used on one line. The distance between them was equal and their dimensions $6 \times 5 \times 3.75 \times 1 \mathrm{~cm}$. The distance of blocks from sluice gate is about $0.32 \mathrm{~m}$. The enter velocity of water was $(216 \mathrm{~cm} / \mathrm{sec})$, the discharge was $\left(70 \mathrm{~m}^{3} / \mathrm{h}\right)$ with Froud number (3.98). The model simulation is in a half of the channel by choosing the symmetry in ZX plane. Figure 1 shows the dimensions of block.

Corresponding Author: Haitham A. Huseein, Department of Civil Engineering, AL-Nahrain University, Al-Jadriya, Baghdad, Iraq 


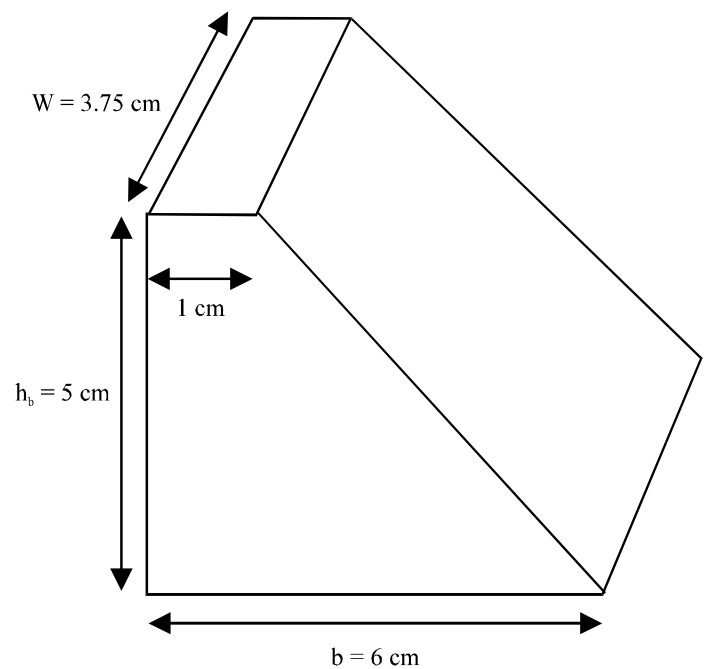

Fig. 1: The dimensions of baffle block

Numerical model: The numerical solution of the equations governing the flow of fluids has mainly been achieved by the finite element technique. The application of the finite element method in the field of fluid mechanics represents a relatively recent development. The objectives of this study are to present the application of the finite element method for the solution of fluid flow problems. Continuity equation comes from the law of conservation of mass:

$$
\frac{\partial \mathrm{p}}{\partial \mathrm{t}}+\frac{\partial\left(\mathrm{pV}_{\mathrm{x}}\right)}{\partial \mathrm{x}}+\frac{\partial\left(\mathrm{pV}_{\mathrm{y}}\right)}{\partial \mathrm{y}}+\frac{\partial\left(\mathrm{pV}_{\mathrm{z}}\right)}{\partial \mathrm{z}}=0
$$

It can use change of pressure rate and the rate at which density changes with pressure instead of change of density rate:

$$
\frac{\partial \mathrm{p}}{\partial \mathrm{t}}=\frac{\partial \mathrm{p}}{\partial \mathrm{P}} \frac{\partial \mathrm{P}}{\partial \mathrm{t}}
$$

The derivative of the density evaluation with respect to pressure comes from the state equation. If the algorithm of incompressible solution is used, the user can be controlled the specification of the value with:

$$
\mathrm{P}=\frac{\mathrm{P}}{\mathrm{RT}} \Rightarrow \frac{\partial \mathrm{p}}{\partial \mathrm{P}}=\frac{1}{\mathrm{RT}}
$$

Momentum equation: The relationship between the stress and deformation rate of the fluid in a Newtonian fluid (in index notation) is:

$$
\mathrm{T}_{\mathrm{ij}}=-\mathrm{P} \delta_{\mathrm{ij}}+\mu\left(\frac{\partial \mathrm{u}_{\mathrm{i}}}{\partial \mathrm{x}_{\mathrm{j}}}+\frac{\partial \mathrm{u}_{\mathrm{j}}}{\partial \mathrm{x}_{\mathrm{i}}}\right)+\delta_{\mathrm{ij}} \lambda \frac{\partial \mathrm{u}_{\mathrm{i}}}{\partial \mathrm{x}_{\mathrm{i}}}
$$

The equations of momentum, without any assumptions regarding the properties are as follows:

$$
\begin{aligned}
& \frac{\partial \mathrm{pV}_{\mathrm{x}}}{\partial \mathrm{t}}+\frac{\partial\left(\mathrm{pV}_{\mathrm{z}} \mathrm{V}_{\mathrm{z}}\right)}{\partial \mathrm{x}}+\frac{\partial\left(\mathrm{pV}_{\mathrm{y}} \mathrm{V}_{\mathrm{z}}\right)}{\partial \mathrm{y}}+ \\
& \frac{\partial\left(\mathrm{pV}_{\mathrm{z}} \mathrm{V}_{\mathrm{z}}\right)}{\partial \mathrm{z}}=\rho \mathrm{g}_{\mathrm{z}}-\frac{\partial \mathrm{P}}{\partial \mathrm{x}}+\mathrm{R}_{\mathrm{z}}+\frac{\partial}{\partial \mathrm{x}}\left(\mu_{\mathrm{e}} \frac{\partial \mathrm{V}_{\mathrm{z}}}{\partial \mathrm{x}}\right)+ \\
& \frac{\partial}{\partial \mathrm{y}}\left(\mu_{\mathrm{e}} \frac{\partial \mathrm{V}_{\mathrm{z}}}{\partial \mathrm{y}}\right)+\frac{\partial}{\partial \mathrm{z}}\left(\mu_{\mathrm{e}} \frac{\partial \mathrm{V}_{\mathrm{z}}}{\partial \mathrm{z}}\right)+\mathrm{T}_{\mathrm{z}} \\
& \frac{\partial \mathrm{pV}_{\mathrm{z}}}{\partial \mathrm{t}}+\frac{\partial\left(\mathrm{pV}_{\mathrm{z}} \mathrm{V}_{\mathrm{z}}\right)}{\partial \mathrm{x}}+\frac{\partial\left(\mathrm{pV}_{\mathrm{y}} \mathrm{V}_{\mathrm{z}}\right)}{\partial \mathrm{y}}+ \\
& \frac{\partial\left(\mathrm{pV}_{\mathrm{z}} \mathrm{V}_{\mathrm{z}}\right)}{\partial \mathrm{z}}=\rho \mathrm{g}_{\mathrm{z}}-\frac{\partial \mathrm{P}}{\partial \mathrm{x}}+\mathrm{R}_{\mathrm{z}}+\frac{\partial}{\partial \mathrm{x}}\left(\mu_{\mathrm{e}} \frac{\partial \mathrm{V}_{\mathrm{z}}}{\partial \mathrm{x}}\right)+ \\
& \frac{\partial}{\partial \mathrm{y}}\left(\mu_{\mathrm{e}} \frac{\partial \mathrm{V}_{\mathrm{z}}}{\partial \mathrm{y}}\right)+\frac{\partial}{\partial \mathrm{z}}\left(\mu_{\mathrm{e}} \frac{\partial \mathrm{V}_{\mathrm{z}}}{\partial \mathrm{z}}\right)+\mathrm{T}_{\mathrm{z}}
\end{aligned}
$$

$R_{x}$ and $R_{z}$ are the terms indicate any terms of source that added by the user. Examples of this contain flow through porous media and screens.

$T_{x}$ and $T_{z}$ are indicated viscous loss terms which were eliminated in the incompressible, constant property case. The differentiation order is reversed in each term, decreasing the term to a derivative of the equation of continuity which was zero:

$$
\begin{aligned}
& \mathrm{T}_{\mathrm{x}}=\frac{\partial}{\partial \mathrm{x}}\left(\mu \frac{\partial \mathrm{V}_{\mathrm{x}}}{\partial \mathrm{x}}\right)+\frac{\partial}{\partial \mathrm{y}}\left(\mu \frac{\partial \mathrm{V}_{\mathrm{y}}}{\partial \mathrm{x}}\right)+\frac{\partial}{\partial \mathrm{z}}\left(\mu \frac{\partial \mathrm{V}_{\mathrm{z}}}{\partial \mathrm{x}}\right) \\
& \mathrm{T}_{\mathrm{z}}=\frac{\partial}{\partial \mathrm{x}}\left(\mu \frac{\partial \mathrm{V}_{\mathrm{z}}}{\partial \mathrm{z}}\right)+\frac{\partial}{\partial \mathrm{y}}\left(\mu \frac{\partial \mathrm{V}_{\mathrm{y}}}{\partial \mathrm{z}}\right)+\frac{\partial}{\partial \mathrm{z}}\left(\mu \frac{\partial \mathrm{V}_{\mathrm{z}}}{\partial \mathrm{z}}\right)
\end{aligned}
$$

Turbulence means that the immediate velocity is fluctuating at all point in the flow field. The velocity is thus, expressed in terms of component of fluctuating and a mean value:

$$
\mathrm{V}_{\mathrm{z}}=\overline{\mathrm{V}_{\mathrm{z}}}+\dot{\mathrm{V}}_{\mathrm{x}}
$$

Where:

$\overline{\mathrm{V}_{\mathrm{x}}}=$ The velocity component in $\mathrm{x}$-direction
$\mathrm{V}_{\mathrm{x}}=$ Fluctuating velocity component in $\mathrm{x}$-direction

Such as this expression is used for the immediate velocity in the equations of Navier-Stokes, the equations may then be time averaged, noting that the time average of the component that fluctuating is zero and the age of the time of the immediate value is the average value. For the integration the time interval is arbitrarily chosen as long enough for this to be true and short enough, so that, "real time" transient impacts don't influence this integration: 


$$
\frac{1}{\delta_{t}} \sum_{0}^{\delta_{t}} \mathrm{~V}_{x} \mathrm{dt}=0, \frac{1}{\delta_{t}} \sum_{0}^{\delta_{t}} \dot{V}_{x} \mathrm{dt}=\overline{\mathrm{V}_{x}}
$$

When Eq. 12 is compensated by the momentum equation, the time averaging cause extra terms. The velocities were the averaged ones in the momentum equations, we drop the bar in the later expression of the equations of momentum, therefore, the bar absence now means the mean value. The extra terms are:

$$
\begin{aligned}
& \left.\left.\sigma R_{x}=\frac{\partial}{\partial x} \overline{\left(p \dot{V}_{x} \dot{V}_{x}\right)}-\frac{\partial}{\partial y} \overline{\left(p \dot{V}_{x} \dot{V}_{y}\right.}\right)-\frac{\partial}{\partial z} \overline{\left(p \dot{V}_{x} \dot{V}_{z}\right.}\right) \\
& \left.\left.\sigma R_{z}=\frac{\partial}{\partial x} \overline{\left(p \dot{V}_{z} \dot{V}_{z}\right.}\right)-\frac{\partial}{\partial y} \overline{\left(p \dot{V}_{z} \dot{V}_{y}\right.}\right)-\frac{\partial}{\partial z} \overline{\left(p \dot{V}_{z} \dot{V}_{z}\right)}
\end{aligned}
$$

where, $\sigma_{R}=$ Reynolds stress terms. The principle favorable position of this procedure originates from the perception that the portrayal of $\sigma_{\mathrm{R}}$ is the very same frame as that of the dispersion terms in the original equations.
The two terms can be joined if the active viscosity is defined as the sum of the viscosity that is laminar and turbulent viscosity:

$$
\mu_{e}=\mu+\mu_{t}
$$

The solution to the problem of the turbulence then rotates around the solution of the turbulent viscosity (Akan, 2011).

\section{RESULTS AND DISCUSSION}

When the result is displayed as a contour, the location is selected as symmetry and the variables are pressure, velocity and volume fraction. Figure 2 shows the volume fraction at open channel, the water direction from right to left, the red color indicates the water and the blue color indicates the air. Figure 3 shows the velocity results at open channel, the high velocity is $-2.16 \mathrm{~m} / \mathrm{sec}$. The negative signal indicates the direction of the water towards the left direction and is reduced to (4.912e-001) the lowest possible in green color. Figure 4

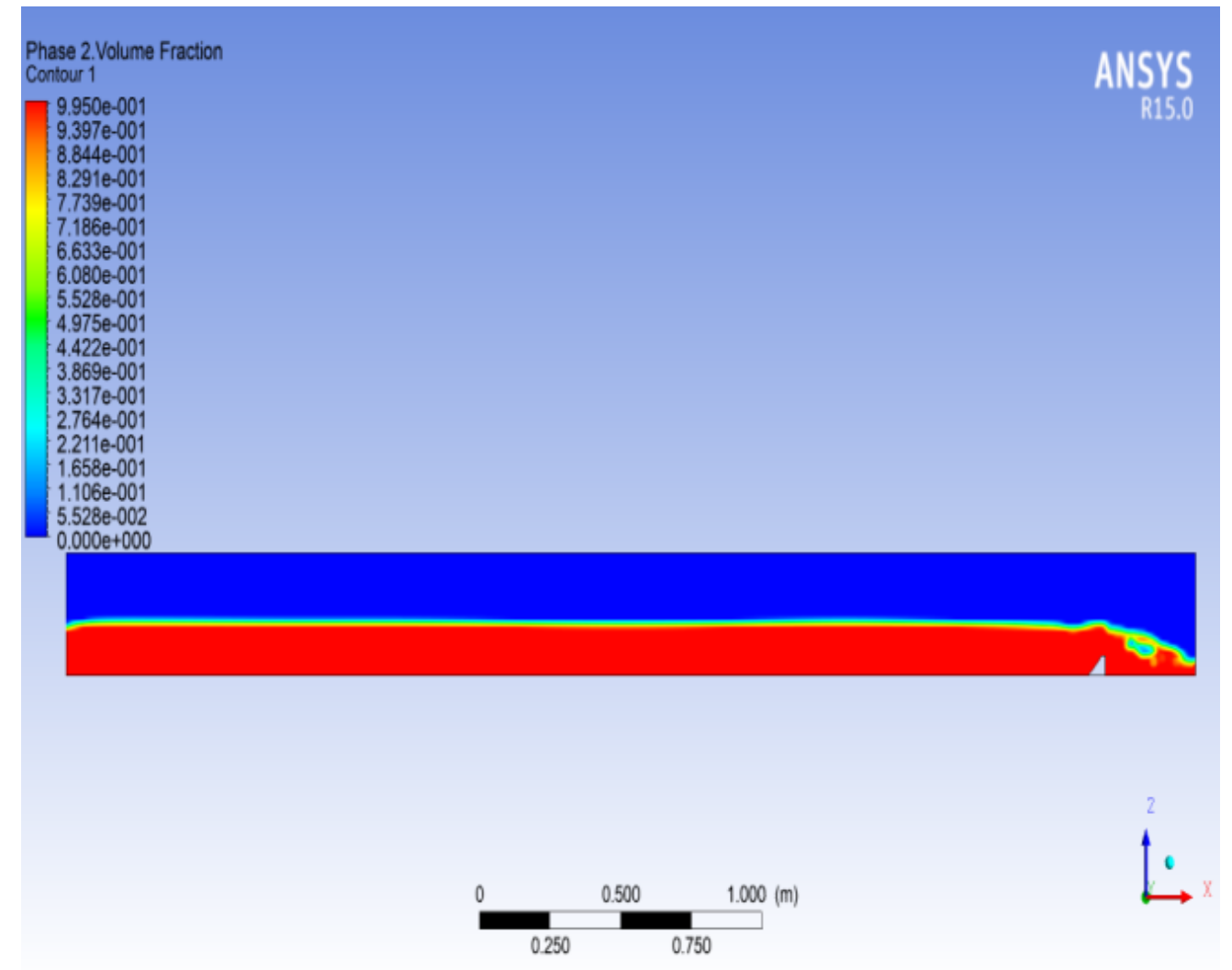

Fig. 2: Contour of volume fraction of open channel flow 
J. Eng. Applied Sci., 14 (17): 6312-6316, 2019

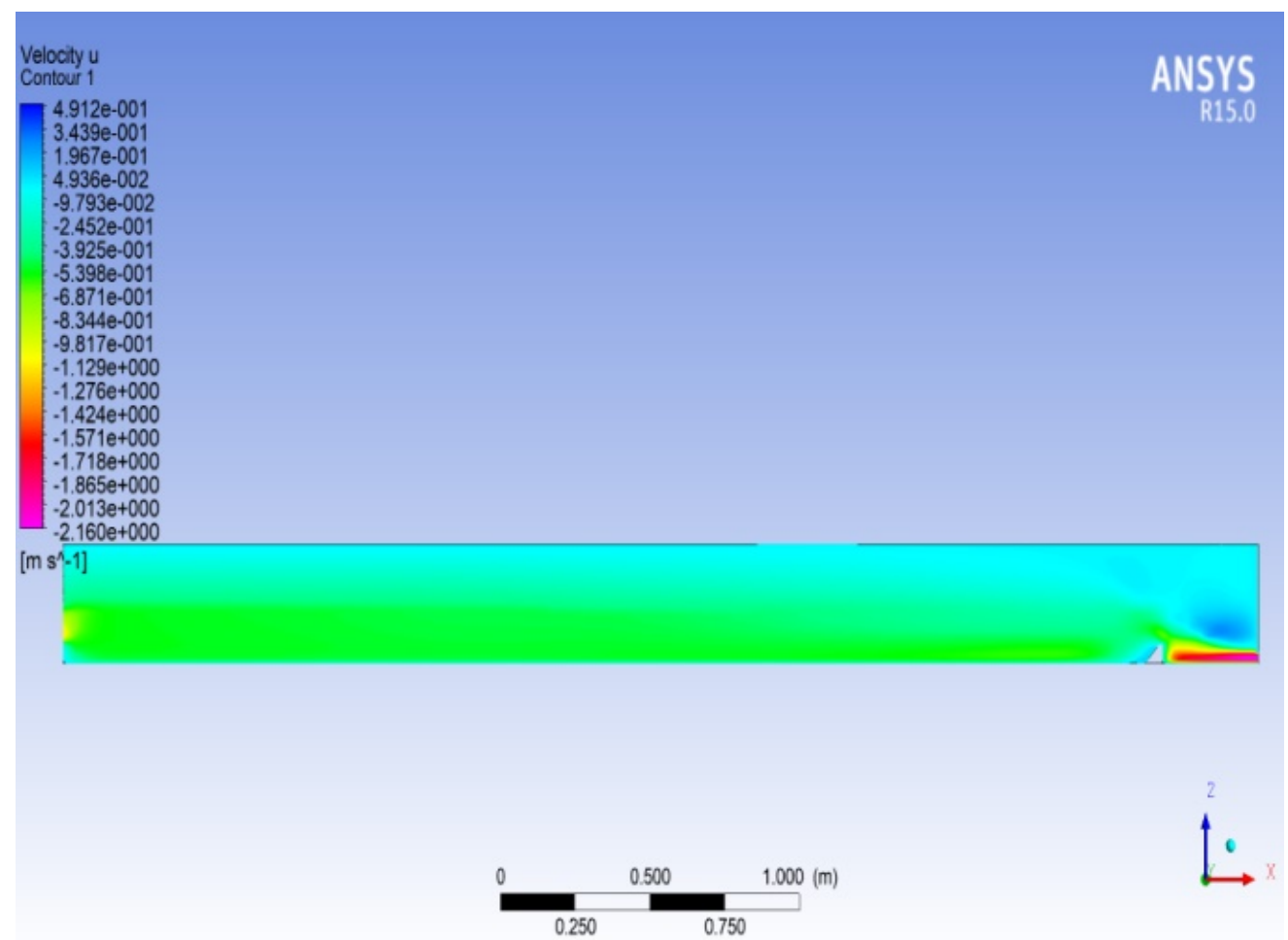

Fig. 3: Contour of velocity of open channel flow

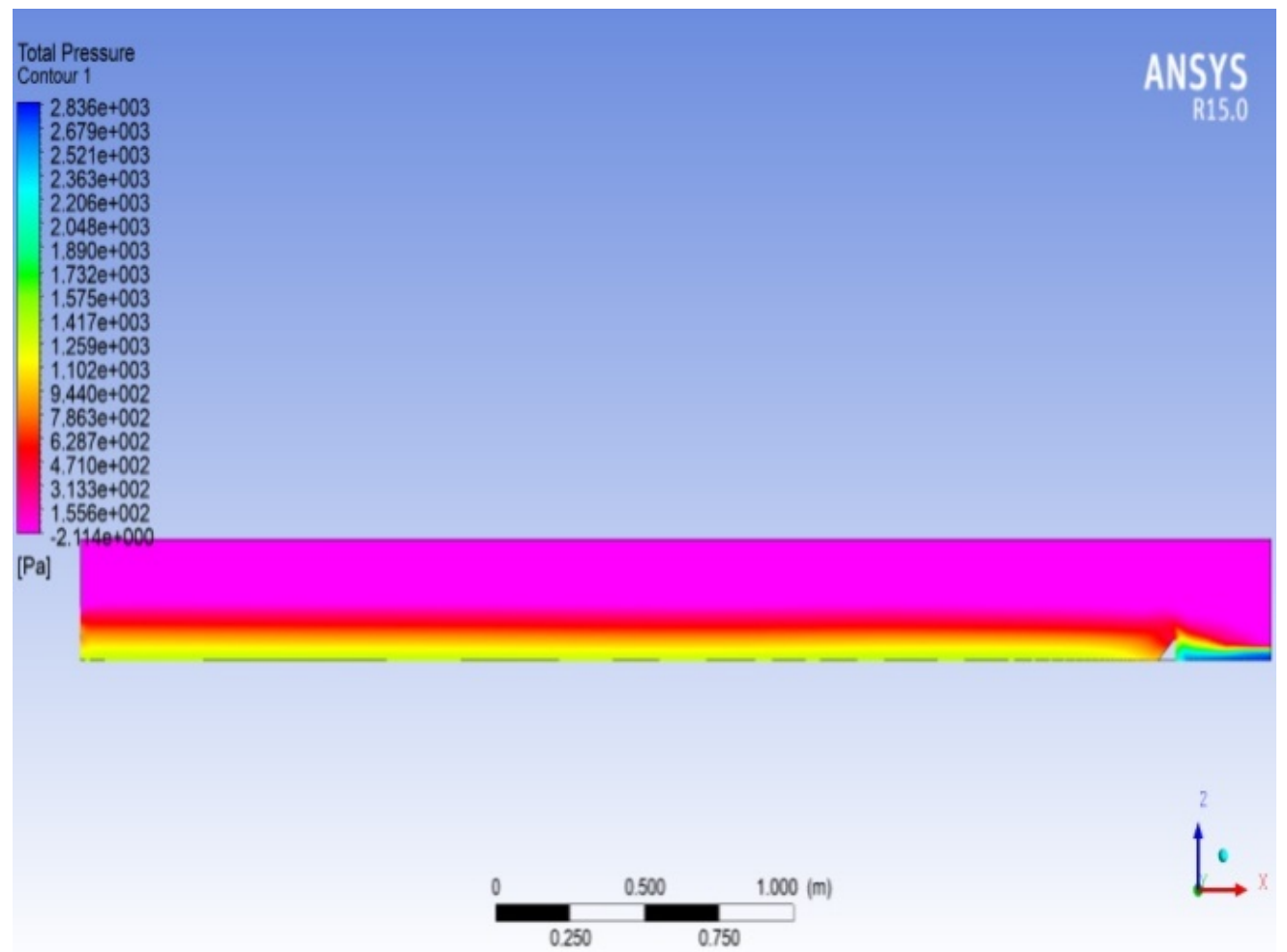

Fig. 4: Contour of pressure of open channel flow 


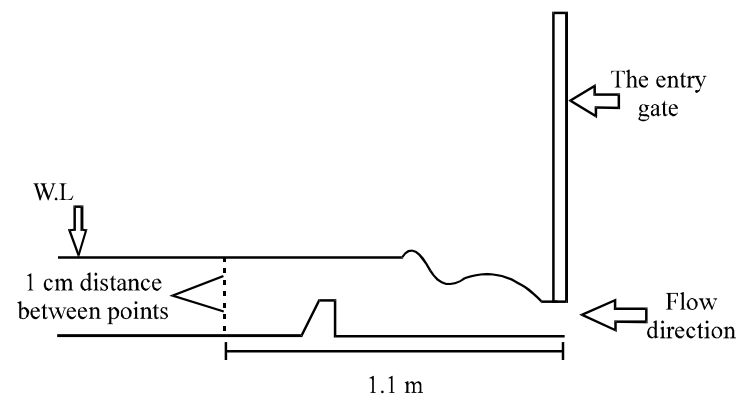

Fig. 5: Open channel model and velocity point's measurements

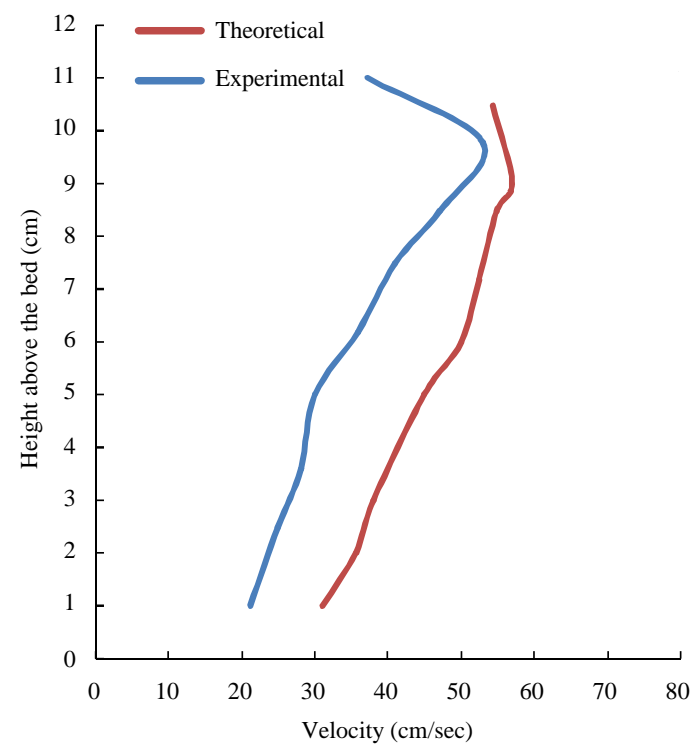

Fig. 6: Validation results of open channel flow

shows the pressure results at open channel, the high pressure is $2.836 \times 10^{3} \mathrm{~Pa}$ and minimum pressure is -2.114 .

The flow velocity is selected for comparison as well as it is affected on the stability of the block structure at the channel. The location of velocity profile in open channel is $1.1 \mathrm{~m}$ from sluice gate. The velocity profile consist of 9 points in vertical section. The space between every vertical point is $1 \mathrm{~cm}$. In this study, the relationship between the velocity and the height of water above the bed are conducted. Figure 5 shows the open channel with location of block, 9 points were taken at a distance of $1.1 \mathrm{~m}$ from the entry gate after the blocks at different heights the distance between each height is approximately $1 \mathrm{~cm}$. Table 1 shows the models validation between experimental and mathematical velocity. Figure 6 illustrated the results of velocity profile and validation of experimental and numerical model.
Table 1: Models validation between experimental and mathematical velocity $\begin{array}{lll}\text { Height }(\mathrm{cm}) \quad \text { Experimental velocity }(\mathrm{cm} / \mathrm{sec}) & \text { CFD velocity }(\mathrm{cm} / \mathrm{sec})\end{array}$

\begin{tabular}{lll}
\hline 1 & 21.0 & 39.0 \\
2 & 25.0 & 42.0 \\
3 & 28.0 & 44.4 \\
4 & 30.0 & 46.0 \\
6 & 36.0 & 52.5 \\
7 & 41.0 & 55.0 \\
8.5 & 47.0 & 57.0 \\
9 & 53.0 & 59.0 \\
10.5 & 37.2 & 54.5 \\
\hline
\end{tabular}

\section{CONCLUSION}

In this research, the previous experimental results are compared with the mathematical solution which simulated by the ANSYS program. The flow velocity after the blocks structure are investigated at several points. It is observed that $2 \mathrm{D}$ CFD Model is a good descriptor of the experimental measurements and a good agreement is evident between the CFD and physical Model.

\section{REFERENCES}

Abdelhaleem, F.S.F., 2013. Effect o f semi-circular baffle blocks on local scour downstream clear-overfall weirs. Ain Shams Eng. J., 4: 675-684.

Akan, A.O., 2011. Open Channel Hydraulics. 1st Edn., Elsevier Publishing Company, Amsterdam, Netherlands, ISBN:9780080479804, Pages: 384.

Bessaih, N. and A. Rezak, 2002. Effect of baffle blocks with sloping front face on the length of the jump. J. Civ. Eng., 30: 101-108.

Chanson, H., 2004. The Hydraulics of Open Channel flow: An Introduction. 2nd Edn., Elsevier Butterworth Heinemann, Oxford, UK., ISBN:9780750659789, Pages: 650 .

Eloubaidy, A.F., J.H. Al-Baidhani and A.H. Ghazali, 1999. Dissipation of hydraulic energy by curved baffle blocks. Pertanika J. Sci. Technol., 7: 69-77.

Ibrahim, M., 2017. Improve the efficiency of stilling basin using different types of blocks. Am. J. Eng. Res., 6: 295-304.

Rozainy, M.R.M.A.Z., I. Shafiq, H.A. Hussein, M.K. Abdullah and I. Abustan et al., 2017. Investigation of stilling basin performance by using physical model and computational fluid dynamics. AIP. Conf. Proc., 1885: 020102-020102. 